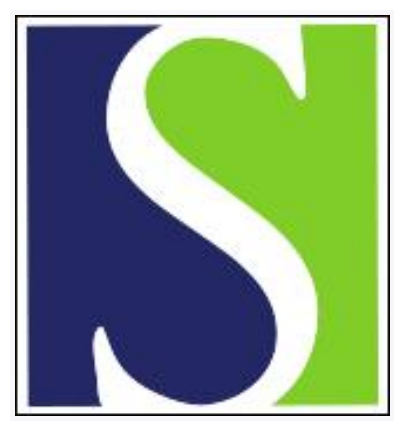

Scand J Work Environ Health 1990;16(2):121-128

https://doi.org/10.5271/sjweh.1808

Issue date: 01 Apr 1990

Indoor air quality and personal factors related to the sick building syndrome.

by Norback D, Michel I, Widstrom J

Affiliation: Department of Occupational Medicine, University Hospital, Uppsala, Sweden.

This article in PubMed: www.ncbi.nlm.nih.gov/pubmed/2353195

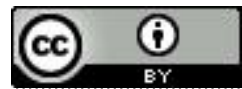




\title{
Indoor air quality and personal factors related to the sick building syndrome
}

\author{
by Dan Norbäck, BA, Ingegerd Michel, MSc, John Widström, MHSc ${ }^{1}$
}

\begin{abstract}
NORBÄCK D, MICHEL I, WIDSTRÖM J. Indoor air quality and personal factors related to the sick building syndrome. Scand J Work Environ Health 1990;16:121-8. The "sick building syndrome" involves symptoms such as eye, skin and upper airway irritation, headache, and fatigue. A multifactorial study was performed among personnel in consecutive cases of sick buildings to investigate relationships between such symptoms, exposure to environmental factors, and personal factors. The total indoor hydrocarbon concentration was significantly related to symptoms. Other indoor exposures such as room temperature, air humidity, and formaldehyde or carbon dioxide concentration did not correlate with the symptoms. Personal factors such as reported hyperreactivity and sick leave due to airway diseases were strongly related to the sick building syndrome. Other factors associated with the sick building syndrome were smoking, psychosocial factors, and experience of static electricity at work. Neither atopy, age, sex, nor outdoor exposures correlated significantly with the number of symptoms. It was concluded that the sick building syndrome is of multifactorial origin and related to both indoor hydrocarbon exposure and individual factors.
\end{abstract}

Key terms: building ventilation, carbon dioxide, hyperreactivity, meteorological factors, occupational exposure, psychosocial factors, static electricity, statistical modeling, tobacco smoking, volatile organic compounds.

In the past, occupational medicine dealt mainly with severe diseases related to long-term or high-level exposure to specific chemicals in the work environment. However, during the last decade, concern has increased about the more subtle health effects of low-level exposure to complex mixtures of chemicals.

One such new area is the possible health effects related to poor indoor air quality in certain nonindustrial buildings, often described as "sick" buildings. As defined by a working group of the World Health Organization, the "sick building syndrome" involves various nonspecific symptoms such as eye, skin and upper airway irritation, headache, and fatigue (1). Although several investigators have reported a higher prevalence of symptoms among persons working in certain "sick buildings" than among workers in other buildings (2-9) and many different chemicals have been quantified in indoor air $(9,10-15)$, only a few investigations have studied the influence of specific indoor exposures on the prevalence of the sick building syndrome (6). In addition, only few investigations have taken into consideration the influence of personal $(6$, $16)$ and outdoor climatological $(17,18)$ factors on the prevalence of the syndrome.

Earlier studies have indicated that room temperature, formaldehyde, carbon dioxide concentration, and building age should be taken into consideration in in-

\footnotetext{
1 Department of Occupational Medicine, University Hospital, Uppsala, Sweden.
}

Reprint requests to: Mr D Norbäck, Department of Occupational Medicine, Akademiska sjukhuset, S-751 85 Uppsala, Sweden. vestigations of the indoor climate. A high room temperature may enhance the prevalence of the sick building syndrome $(19,20)$. A relation between indoor formaldehyde concentration and the sick building syndrome has earlier been demonstrated $(21,22)$. Measurements of carbon dioxide can be used to indicate the degree of fresh air supply in relation to the number of individuals in a building, and a concentration of $0.08 \mathrm{vol} \%$ of carbon dioxide ( $800 \mathrm{ppm}$ ) has been suggested as a control limit value (10). A negative association between building age and the prevalence of symptoms has also been demonstrated (6).

This study was performed in order to study the influence of indoor and outdoor exposures and personal factors on the occurrence of symptoms among personnel in presumedly "sick" buildings.

\section{Methods}

Since March 1984, the Department of Occupational Medicine at the University Hospital in Uppsala has offered a specific combination of a self-administered questionnaire and exposure measurements as a means of investigating workplaces in sick buildings. Consequently, occupational health care centers in the tricounty region (the counties of Gävleborg, Kopparberg and Uppsala) have spontaneously referred presumed cases of sick building syndrome to our department. This tricounty region contains 84 health care units serving 140000 employees in the public sector and 120000 employees in the private sector.

The study was based on all consecutive cases of sick buildings $(\mathrm{N}=11)$ with more than 10 employees re- 
ferred to the Department of Occupational Medicine during a three-year period (March 1984-April 1987). For statistical reasons, workplaces with less than 10 employees were excluded from the material.

These 11 sick buildings were selected by the occupational health care centers to be investigated by us. In addition, information on those sick buildings known by the health care centers but not referred to us $(\mathrm{N}=44)$ were obtained from a sick-building survey performed later, during 1988 (23). This information was used to compare the building characteristics of the referred sick buildings with those of sick buildings not referred to us to determine whether the studied sick buildings were representative for all known sick buildings in the region. The workplace characteristics of the referred and nonreferred sick buildings are presented in table 1 . The

Table 1. Selected workplace characteristics among the referred sick buildings in comparison with sick buildings ${ }^{a}$ not referred to the Department of Occupational Medicine.

\begin{tabular}{lcc}
\hline Characteristics & $\begin{array}{c}\text { Prevalence in } \\
\text { referred sick } \\
\text { buildings (\%) } \\
(\mathrm{N}=11)\end{array}$ & $\begin{array}{c}\text { Prevalence in } \\
\text { nonreferred sick } \\
\text { buildings (\%) } \\
(\mathrm{N}=44)\end{array}$ \\
\hline Public sector workplace & 100 & 73 \\
Small workplace $^{\mathrm{b}}$ & 36 & 41 \\
New building & 82 & 59 \\
$\begin{array}{l}\text { Office workplace } \\
\text { Child care workplace }\end{array}$ & 45 & 18 \\
$\begin{array}{l}\text { Forced mechanical } \\
\text { ventilation }\end{array}$ & 45 & 48 \\
$\begin{array}{l}\text { Air conditioning (air } \\
\text { cooling or humidification) }\end{array}$ & 91 & 100 \\
$\begin{array}{l}\text { Wall-to-wall carpets } \\
\text { in the workplaces }\end{array}$ & 9 & 7 \\
\hline
\end{tabular}

a Workplaces with at least ten employees known to be "sick" by the occupational health centers in the tricounty region before 1987.

b Workplaces with 10-19 employees.

c Built after the so-called "energy crisis" (1974).

d Primary schools or day care centers.

Table 2. Selected demographic and exposure data for sick building personnel $(\mathrm{N}=261)$.

\begin{tabular}{lc}
\hline Characteristics & $\begin{array}{c}\text { Percentage of } \\
\text { total number }\end{array}$ \\
\hline Proportion of women & 79 \\
Current tobacco smokers & 23 \\
Individuals with signs of atopya & 18 \\
Nonspecific hyperreactivity & 33 \\
Environmental tobacco smoke exposurec & 4 \\
Reported exposure to static electricityd & 11 \\
Work with video display units & 6 \\
Wall-to-wall carpet in the workplace & 6 \\
\hline & \\
a Individuals with a history of asthma, hayfever or eczema in & \\
childhood. & \\
b Easily irritated eyes or respiratory tract during exposure to \\
nonspecific irritants (tobacco smoke, exhaust gases, organic \\
solvents).
\end{tabular}

majority of the buildings were new buildings in the public sector equipped with mechanical ventilation. Air cooling, air humidification, and wall-to-wall carpets were rare.

\section{Assessment of symptoms and personal factors}

The six-month prevalence of symptoms among the persons working in the sick buildings were recorded by means of a self-administered questionnaire. The questionnaire contained queries on individual factors such as smoking habits, atopy, hyperreactivity, sick leave, work stress, work satisfaction, and climate of cooperation at work. The nonresponse rate was less than $5 \%$ in all of the sick buildings. The mean age of the employees was 41 years, and the mean number of reported days of sick leave due to respiratory illness was $5 \mathrm{~d}$ during the last six months. Other demographic and exposure data for the responding sick building personnel are presented in table 2 . In order to avoid any influence of the results of the exposure measurements on the questionnaire responses, the questionnaire investigation was always completed before the exposures were measured. In all cases, the questionnaire investigations were performed during the heating season (October-April).

The questionnaire included "yes"/"no" questions on 16 different symptoms covering the last six months. No information on the severeness or the duration of the symptoms was gathered. Since the sick building syndrome comprises different symptoms, a single effect variable was created through the calculation of a symptom score ranging from 0 to 16 for each individual. In addition, the prevalence of the different symptoms was also calculated. Work stress, work satisfaction, and climate of cooperation during the last six months were measured by analogue rating scales (24). A psychosocial index ranging from 0 to $100 \%$ was calculated through the addition of the perceived degree of work dissatisfaction, work stress, and lack of work cooperation. The symptom questions and the analogue rating scales appear in the appendix.

\section{Assessment of exposure}

Initially, information about the workplaces was obtained from the occupational health centers to which the workplaces were connected. This information included building age, type of work, type of employment, number of employees, type of floor covering, and type of ventilation, air humidification and air conditioning. The same type of information was gathered for both the referred cases and those cases of sick buildings known to the health care centers but not referred to us.

In addition, chemical and climatological measurements were performed in the referred sick buildings. Room temperature and relative humidity were recorded with an Assman psychrometer. Indoor formaldehyde concentration was measured with glass fiber filters im- 
pregnated with 2,4-dinitrophenylhydrazine (25), the air sampling rate being $0.25 \mathrm{l} / \mathrm{min}$ for $2 \mathrm{~h}$. The filters were analyzed by liquid chromatography. The indoor carbon dioxide concentration was measured by colorimetric detector tubes (Dräger $0.01 \% / a$ ).

The volatile organic compounds in the indoor and outdoor air were sampled on charcoal sorbent tubes (SKC 226-01), the air sampling rate being $11 / \mathrm{min}$ for $2 \mathrm{~h}$. In order to avoid moisture interference with the absorption of the hydrocarbons, the measurements were performed during October-April, when the relative humidity of the indoor air in this part of Sweden is low $(10-40 \%)$.

The charcoal tubes were kept at $-20^{\circ} \mathrm{C}$ until analysis. The charcoal tubes were desorbed with $1 \mathrm{ml}$ of carbon disulfide prior to the analysis, which was performed within a week of the sampling day with a gas chromatograph (Hewlett Packard model 5880) equipped with a flame ionization detector and packed glass columns. The injector temperature was $150^{\circ} \mathrm{C}$, the detector temperature was $200^{\circ} \mathrm{C}$, and the flow of the carrier gas nitrogen was $30 \mathrm{ml} / \mathrm{min}$. Fifteen common hydrocarbons were identified and quantified through the use of an external standard technique. These hydrocarbons were identified through comparison of the retention times of the samples with the retention times of the standards on two different columns. When the low-boiling uncalibrated peaks (C3-C12) were quantified, the response factor of n-decane was used. When the high-boiling unknown hydrocarbons ( $>\mathrm{C} 12$ ) were quantified, the response factor of a mixture of high boiling hydrocarbons (dodecyl benzenes) was used. The total air concentration of the identified and unidentified hydrocarbons was calculated.

The number of measurements performed in each workplace depended on the size of the building. In larger workplaces, the number of measurements was greater to enable the calculation of a more representative average exposure for the workplace. For air temperature, air humidity, and carbon dioxide, two to eight short-term measurements were taken. For the charcoal-sampled indoor hydrocarbon measurements, two to five individual 2 -h average samples were taken. For formaldehyde one or two 2-h measurements were taken. For the outdoor hydrocarbon measurements, one individual 2-h average sample was taken. Arithmetic average exposures were calculated for each sick building workplace.

Data on average temperature, precipitation, and average atmospheric pressure during the month when the questionnaire was distributed to the different sick buildings were obtained from the Swedish Meteorological and Hydrological Institute in Norrköping.

\section{Statistical methods}

The differences in the proportions were calculated by the two-tailed chi-square test or by Fisher's exact test for $2 \times 2$ contingency tables (26). Geometric means and geometric standard deviations, as proposed by Saltzman (27) were used in the calculation of the variation of different indoor exposures between workplaces. The multifactorial analysis of the data was performed by multiple linear regression, using the symptom score as the dependent variable. Logarithmic values of the indoor volatile hydrocarbon concentrations and building age were used in the regression model for a reasonable symmetry of distribution of these variables.

Two different strategies for entering variables into the regression model were used to ensure that the conclusions were not influenced by the variable selection procedure. In the first strategy, conventional stepwise regression $(\mathrm{P}<0.05)$ was performed, with no forcedin variables. In the second, the analysis was performed in four steps. As a first step, all potential confounders were forced into the model. Second, all significant confounders $(\mathrm{P}<0.05)$ were maintained in the model. Third, the exposure variables were forced into the model one by one. Fourth, all the significant exposure variables were included in the model. Finally, all nonsignificant exposure variables were excluded.

\section{Results}

Few individuals were annoyed by environmental tobacco smoke, worked at a video display terminal, or had wall-to-wall carpets in their workplaces. The effects of these rare exposures were not analyzed further.

Symptoms from the eyes, nose, and throat, and also tiredness and headache, were common in the referred sick buildings. Nausea and dermal symptoms were less common (table 3 ).

The average indoor concentration for the sum of compounds differed with one or two orders of magnitude between the different sick buildings (table 4). The greatest variation was found for terpenes and unidentified low-boiling hydrocarbons. The largest

Table 3. Symptom prevalence during the last six months in the total material of sick building personnel $(N=261)$.

\begin{tabular}{lcr}
\hline Symptom & $\begin{array}{c}\text { Total mean } \\
\text { prevalence (\%) }\end{array}$ & Range $^{a}$ \\
\hline Eye irritation & 36 & $13-67$ \\
Swollen eyelids & 13 & $0-32$ \\
Nasal catarrh & 21 & $7-46$ \\
Nasal congestion & 33 & $12-54$ \\
Dryness in the throat & 38 & $13-64$ \\
Sore throat & 18 & $8-36$ \\
Irritative cough & 15 & $6-27$ \\
Headache & 36 & $19-60$ \\
Abnormal tiredness & 49 & $19-92$ \\
Sensation of getting a cold & 42 & $23-77$ \\
Nausea & 8 & $0-23$ \\
Facial itch & 12 & $0-31$ \\
Facial rash & 14 & $0-38$ \\
Itching on the hands & 12 & $5-31$ \\
Rashes on the hands & 8 & $0-23$ \\
Eczema & 15 & $5-26$ \\
\hline
\end{tabular}

a Range of arithmetic mean prevalence in each sick building. 
Table 4. Variation of indoor air concentration $\left(\mu \mathrm{g} / \mathrm{m}^{3}\right)$ of chemical compounds between sick building workplaces $(\mathrm{N}=11)$.

\begin{tabular}{|c|c|c|c|c|}
\hline Compounds & $\begin{array}{l}\text { Arithmetic } \\
\text { mean }\end{array}$ & $\begin{array}{l}\text { Geometric } \\
\text { mean }\end{array}$ & $\begin{array}{l}\text { Geometric } \\
\text { SD }\end{array}$ & Range \\
\hline Formaldehyde & 11 & 10 & 2.3 & $<10-30$ \\
\hline Aromates $^{\mathrm{a}}$ & 34 & 21 & 2.6 & $50-110$ \\
\hline n-Alkanes ${ }^{b}$ & 11 & 8 & 2.2 & $3-24$ \\
\hline Terpenes $^{c}$ & 38 & 16 & 5.1 & $2-140$ \\
\hline Butanols ${ }^{d}$ & 3 & 2 & 3.3 & $<1-9$ \\
\hline 2-Ethylhexanol & 2 & 1 & 2.4 & $<1-7$ \\
\hline $\begin{array}{l}\text { Unidentified low- } \\
\text { boiling hydrocarbons }\end{array}$ & 200 & 73 & 4.0 & $10-1300$ \\
\hline $\begin{array}{l}\text { Unidentified high- } \\
\text { boiling hydrocarbons }\end{array}$ & 40 & 16 & 3.2 & $<5-270$ \\
\hline $\begin{array}{l}\text { Total indoor concentration } \\
\text { of voltile hydrocarbons }\end{array}$ & 380 & 210 & 2.6 & $50-1380$ \\
\hline
\end{tabular}

a Sum of toluene, m-xylene, o-xylene, $p$-xylene, and ethylbenzene.

b Sum of n-octane, n-decane, n-decane, and n-undecane.

c Sum of alpha-pinene, delta-carene, and limonene.

d Sum of n-butanol and iso-butanol.

e Sum of unidentified hydrocarbon with a retention time below n-dodecane.

$f$ Sum of unidentified hydrocarbons with a retention time equal to or above n-dodecane.

Table 5. Means and ranges of the climatological and ventilation data from the sick buildings $(\mathrm{N}=11)$.

\begin{tabular}{lcc}
\hline & $\begin{array}{c}\text { Arithmetic } \\
\text { mean }\end{array}$ & Range \\
\cline { 2 - 3 } & 21 & $20-23$ \\
Room temperature $\left({ }^{\circ} \mathrm{C}\right)$ & 34 & $20-47$ \\
$\begin{array}{l}\text { Relative air humidity }(\%) \\
\text { Carbon dioxide concentration } \\
(\mu \mathrm{l} / \mathrm{l})\end{array}$ & 730 & $570-1250$ \\
$\begin{array}{l}\text { Outdoor air rate } \\
\left(1 \cdot \mathrm{s}^{-1} \cdot \text { person }\right.\end{array}$ & & \\
\hline a & & \\
Calculated from the measured carbon dioxide $\left(\mathrm{CO}_{2}\right)$ concen- \\
tration, on the assumption of a $\mathrm{CO}_{2}$ emission of $18 \mathrm{l} / \mathrm{h}$ per \\
individual, equilibrium, and an outdoor $\mathrm{CO}_{2}$ concentration of \\
$330 \mu \mathrm{l} / \mathrm{l}$.
\end{tabular}

Table 6. Variation of meterological and outdoor exposure data for the locations of the sick buildings $(N=11)$. (VOC = volatile organic compounds)

\begin{tabular}{lcc}
\hline & $\begin{array}{c}\text { Arithmetic } \\
\text { mean }\end{array}$ & Range \\
\cline { 2 - 3 } & -3 & $-14-+4$ \\
$\begin{array}{l}\text { Mean outdoor temperature } \\
\left({ }^{\circ} \mathrm{C}\right)\end{array}$ & 1014 & $1008-1022$ \\
$\begin{array}{l}\text { Mean air pressure } \\
\text { (mbar) }\end{array}$ & 43 & $6-88$ \\
$\begin{array}{l}\text { Cumulative precipitation } \\
\text { (mm water) }\end{array}$ & 43 & $15-120$ \\
\hline
\end{tabular}

a Meteorological data for the month when the questionnaire investigation was performed.

b Total outdoor concentration of volatile hydrocarbons.

group of compounds was made up of unidentified lowboiling hydrocarbons. The chromatograms revealed that most of these unidentified compounds were highly volatile compounds with retention times shorter than the retention time of benzene. The indoor and outdoor climatological conditions, the outdoor air rate, and the outdoor hydrocarbon concentration are shown in tables 5 and 6 .

The multiple regression analysis revealed that five individual factors were significantly related to the symptom score. These factors were nonspecific hyperreactivity $(\mathrm{P}<0.001)$, sick leave due to airway illness $(\mathrm{P}<0.001)$, psychosocial dissatisfaction $(\mathrm{P}<0.01)$, own tobacco smoking $(\mathrm{P}<0.01)$, and reported exposure to static electricity $(\mathrm{P}<0.01)$. Among the measured exposures, only total indoor hydrocarbon concentration correlated significantly with the number of symptoms $(\mathrm{P}<0.01)$. Room temperature, air humidity, and carbon dioxide or formaldehyde concentration did not correlate significantly with the symptoms. Neither did building age or any outdoor climatological or exposure variables correlate significantly with the symptom score. The two different strategies used for selecting variables into the analysis resulted in the same final regression model (table 7).

A further multiple regression analysis of the relation between different groups of compounds (table 4) and the number of symptoms, including the five significant confounders in the regression model, was also performed. In this analysis, only unidentified lowboiling hydrocarbons correlated significantly with the symptoms $(P<0.05)$. No identified groups of compounds correlated significantly with the number of symptoms.

The relation between the sick building syndrome and the total hydrocarbon concentration could also be demonstrated in a regression analysis of the average number of symptoms in the different sick building groups as a function of the logarithmic value of the total indoor hydrocarbon concentration $\left(\mathrm{R}^{2}=55 \%\right)$ $(\mathrm{P}<0.01)$ (figure 1$)$. 
Table 7. Multiple linear regression analysis of the individual symptom scores (0 to 16) of the sick building personne $(N=240)$ as a function of five significant predictor variables ${ }^{a}$ $(\mathrm{P}<0.05)$. (SE = standard error, $\mathrm{PSD}=$ psychosocial dissatisfaction index, $\operatorname{VOC}=$ volatile organic compounds)

\begin{tabular}{lcc}
\hline Variable & $\begin{array}{c}\text { Partial } \\
\text { regression } \\
\text { coefficient }\end{array}$ & $\begin{array}{c}\text { SE of } \\
\text { coefficient }\end{array}$ \\
\hline Hyperreactivity $^{\mathrm{b}}$ & $2.51^{\mathrm{c}}$ & 0.38 \\
Sick leave $^{\mathrm{d}}$ & $0.13^{\mathrm{c}}$ & 0.03 \\
PSD index $^{\mathrm{e}}$ & $2.87^{\mathrm{f}}$ & 1.11 \\
Tobacco smoking $^{\mathrm{g}}$ & $1.74^{\mathrm{f}}$ & 0.63 \\
Electrostatically charged $^{\mathrm{b}}$ & $1.97^{\mathrm{f}}$ & 0.55 \\
Total indoor VOc $^{\mathrm{h}}$ & $1.12^{\mathrm{f}}$ & 0.39 \\
\hline
\end{tabular}

a The following 12 variables were not significant $(P>0.05)$ predictors of symptom score: age, sex, atopy, building age, indoor room temperature, indoor air humidity, indoor carbon dioxide concentration, outdoor volatile hydrocarbon concentration, outdoor temperature, air pressure, and precipitation.

b Difference in number of symptoms between individuals answering "yes" and those answering "no" on this question.

c Two-tailed $P<0.001$.

d Number of symptoms per yearly week of sick leave due to airway illness.

e Difference in number of symptoms among individuals with $100 \%$ on the psychosocial dissatisfaction index as compared to those with $0 \%$

f Two-tailed $P<0.01$.

9 Difference in number of symptoms among heavy smokers (>15 cigarettes/d) and nonsmokers.

$h$ Number of symptoms per tenfold change in the indoor hydrocarbon concentration (logarithm of concentration used in the regression).

The relation between the indoor hydrocarbon concentration and different symptoms was also studied in comparisons of the geometric mean exposure among persons with and persons without a particular symptom (table 8 ). For 10 out of 16 symptoms, the mean hydrocarbon exposure was significantly higher among persons with the symptom as compared with persons without the symptom $(\mathrm{P}<0.05)$.

\section{Discussion}

Selection bias can occur as a result of both a low response rate and incorrect study design. The participation rate was high in our study, and therefore the probability of selection bias due to loss of individuals from the studied sick building groups was minimized. The 11 sick building groups were referred to us by the occupational health centers in the region. This procedure might have introduced selection bias since we had no control of the criteria for referring the sick building workplace. However, the prevalence of building or workplace characteristics was similar in the studied sick buildings and sick buildings not referred to our clinic. Thus selection bias coupled to the referring process was less probable. The cross-sectional design of the study could have influenced the result if there had been an accumulation of healthy individuals in buildings with higher levels of indoor pollutants. On the other hand, if enhanced levels of pollutants in certain buildings would cause sensitive individuals to leave such work-
Table 8. Relation between different symptoms and the total indoor volatile hydrocarbon concentration. (VOC $=$ volatile or ganic compounds, NS = not significant)

\begin{tabular}{lcc}
\hline Type of symptom & VOC ratio & $\begin{array}{c}\text { Two-tailed } \\
\text { P-value }^{\mathrm{b}}\end{array}$ \\
\hline Eye irritation & 1.43 & $<0.01$ \\
Swollen eyelids & 2.07 & $<0.001$ \\
Nasal catarrh & 1.65 & $<0.01$ \\
Nasal congestion & 1.43 & $<0.01$ \\
Dryness in the throat & 1.58 & $<0.001$ \\
Sore throat & 1.45 & $<0.05$ \\
Irritative cough & 1.08 & NS \\
Headache & 1.30 & $<0.05$ \\
Abnormal tiredness & 1.72 & $<0.001$ \\
Sensation of getting a cold & 1.45 & $<0.01$ \\
Nausea & 1.53 & NS \\
Facial itch & 1.54 & $<0.05$ \\
Facial rash & 1.16 & NS \\
Itching on the hands & 1.17 & NS \\
Rashes on the hands & 1.31 & NS \\
Eczema & 0.81 & NS \\
\hline
\end{tabular}

a Ratio of geometric mean concentration among individuals with and without the particular symptom.

b Calculated from Student's t-test performed on logarithmic values.

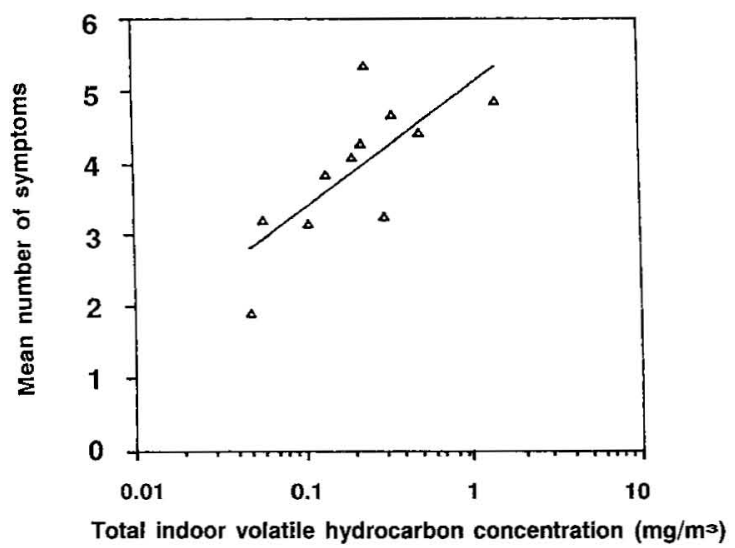

Figure 1. Linear regression values of the mean (arithmetic) number of symptoms (range $0-16$ ) as a function of the total indoor concentration of volatile hydrocarbons (SYMP $=1.79$ $\log _{10}(V O C)+5.13 ; R=0.74$, where SYMP is the mean number of symptoms among the 11 sick building groups, VOC is the indoor mean concentration of total volatile hydrocarbons ( $\mathrm{mg} / \mathrm{m}^{3}$ ), and $\mathrm{R}$ is the correlation coefficient).

places, the cross-sectional design of the study would underestimate the true effect of indoor air pollution.

Another problem regarding the validity is the possible response bias due to awareness of the exposure. This study was performed in presumedly sick buildings where at least some of the individuals believed that their symptoms were related to their workplace. However, the measurements were performed after the questionnaire study was completed, and thus the results of the measurements could not have influenced the questionnaire responses. In addition, only specific ex- 
posures and specific individual factors correlated with the number of symptoms. Finally, in multivariate modeling of epidemiologic data, the strategy of entering the variables into the model may influence the result (28). However, in this study, the two different strategies resulted in the same regression model. In conclusion, it was not probable that the results of our study were due to response or selection bias or to the selection of a particular regression model.

In our study, sick leave due to respiratory illness and symptoms of hyperreactivity in situations outside the sick buildings were the most strongly correlated with the number of symptoms. None of these potential confounders has earlier been studied in other investigations on the sick building syndrome. However, some of the symptoms included in the sick building syndrome are similar to symptoms occurring in common airway infections. In addition, common airway infections may induce temporary bronchial hyperreactivity among normal subjects (29). Very probably, such temporary hyperreactivity also makes the individual more sensitive to irritants at work or in the home environment.

Tobacco smoking correlated with the sick building syndrome. An association between smoking and such symptoms has earlier been demonstrated (6). A relationship between the degree of psychosocial dissatisfaction and the sick building syndrome was also found. This result is in agreement with the findings of two other studies in which both climate of cooperation at work (30) and work stress (16) were found to correlate with symptoms associated with the sick building syndrome.

A relation between self-reported exposure to static electricity and symptoms was also demonstrated. Concerning the possible relation between static electricity and the sick building syndrome, there is conflicting information in the literature. In a recent Swedish study, individuals who often experienced electrostatic shocks in hospital environments without carpeting reported an enhanced prevalence of fatigue (30). In a British study, no such association could be demonstrated (2). There are other studies in which the degree of electrostatic charge was measured among office workers. One study revealed a significant association between the degree of charge and the prevalence of symptoms associated with the sick building syndrome (20). In another study, no such association could be demonstrated (31).

Although chemical stimulation of the trigeminal or olfactory nerves has been suggested as an explanation of the sick building syndrome (32), there are few epidemiologic studies that test this hypothesis. Formaldehyde concentrations one order of magnitude higher than the levels measured in the present study have been shown to correlate with symptoms related to the sick building syndrome $(21,22)$. In the "Town Hall Study," a positive association was found between total hydrocarbon concentration and sick building syndrome in that the highest prevalence of symptoms was found for the building with the highest concentration of total hydrocarbons (6). Besides this study, no epidemiologic studies on the effect of volatile hydrocarbons other than formaldehyde on the sick building syndrome are found in the literature. In our study, the total indoor hydrocarbon concentration, ranging from 0.05 to $1.38 \mathrm{mg} / \mathrm{m}^{3}$, was the exposure measure best correlated with the number of symptoms. Since this study demonstrated an effect of the hydrocarbon concentration on many different symptoms, it is justified to use a symptom score as a simple measure of the sick building syndrome. In a Danish exposure chamber study, the effect of 2-h exposures to a mixture of 20 common indoor hydrocarbons was studied (33). In that investigation, it was shown that, at a total hydrocarbon concentration of $5 \mathrm{mg} / \mathrm{m}^{3}$, the hydrocarbon mixture could induce irritation of the eyes, nose, and throat. The effect was acute and showed no signs of adaptation. In addition, a digit-span performance test also showed decreased scores during exposure. Other human experimental data on the irritative effects of hydrocarbon mixtures similar to indoor air at lower exposure levels than $5 \mathrm{mg} / \mathrm{m}^{3}$ are not available.

The sick buildings in our study were generally wellventilated above the existing ventilation standard of $5-61$ of outdoor air per second and person (10), and no significant association between carbon dioxide concentration and symptoms could be demonstrated. Although carbon dioxide is a good measure of the fresh air supply per individual, it is a reliable indicator of air quality only if humans or human activities are the dominating source of indoor air pollution. As demonstrated by Fanger (34), other nonhuman factors such as the buildings or the ventilation systems could be dominating sources of air pollution in a modern indoor environment. This possibility could explain why no association between symptoms and carbon dioxide concentration could be demonstrated in our study.

We conclude that the sick building syndrome is of multifactorial origin, depending on both personal factors and environmental factors such as the indoor hydrocarbon concentration. Although some types of hydrocarbons might contribute to the irritative symptoms more than other compounds, the sum of hydrocarbons is a simple and convenient measure, which was also found to be better related to the sick building syndrome than the concentration of single groups of compounds. This finding is well in agreement with the hypothesis that the syndrome is best understood as a concurrent effect of sensory irritation from the complex mixture of hydrocarbons occurring in the modern indoor environment. However, since certain personal factors are also correlated with the prevalence of the syndrome, these factors must be carefully controlled in epidemiologic investigations on the sick building syndrome. 


\section{References}

1. Akimenko VV, Andersen I, Lebowitz MD, Lindvall T. The "sick" building syndrome. In: Berglund B, Berglund U, Lindvall T, Sundell J, ed. Indoor air; vol 6 (Evaluation and conclusions for health sciences and technology). Stockholm: Swedish Council for Building Research, 1986:87-97. (D13:1986.)

2. Burge S, Hedge A, Wilson S, Bass JH, Robertson A. Sick building syndrome: a study of 4373 office workers. Ann Occup Hyg 1987;31:493-504.

3. Finnegan MJ, Pickering CAC, Burge PS. The sick building syndrome: prevalence studies. Br Med J 1984;289: $1573-5$.

4. Hedge A. Evidence of a relationship between office design and self-reports of ill health among office workers in the United Kingdom. J Archit Plan Res 1984;1: $163-4$.

5. Robertson AS, Burge PS, Hedge A, et al. Comparison of health problems related to work and environmental measurements in two office buildings with different ventilation systems. Br Med J 1985;291:373-6.

6. Skov $P$, Valbjørn $O$, Danish Indoor Climate Study Group. The "sick" building syndrome in the office environment: the Danish town hall study. Environ Int 1987;13:339-49.

7. Sterling E, Sterling T. The impact of different ventilation levels and fuorescense lighting types on building illness: an experimental study. Can J Public Health 1983; $74: 385-92$

8. Taylor PR, Dell'Acqua BJ, Baptiste MS, Hwang H-L, Sovik RA. Illness in an office building with limited fresh air access. J Environ Health 1984;47:24-7.

9. Turiel I, Hollowell CD, Miksch RR, Rudy JV, Young RA, Coye MJ. The effects of reduced ventilation on indoor air quality in an office building. Atmos Environ 1983;17:51-64.

10. Berglund B, Berglund U, Lindvall T. Characterization of indoor air quality and "sick buildings." ASHRAE Trans 1984;90:1045-55.

11. Berglund $B$, Johansson I, Lindvall T. A longitudinal study of air contaminants in a newly built preschool. Environ Int 1982;8:111-5.

12. Berglund $B$, Johansson I, Lindvall $T$. The influence of ventilation on indoor/outdoor air contaminants in an office building. Environ Int 1982;8:395-9.

13. Jarke FH, Dravnieks A, Gordon SM. Organic contaminants in indoor air and their relation to outdoor contaminants. ASHRAE Trans 1981;87:153-66.

14. Johansson I. Determination of organic compounds in indoor air with potential reference to air quality. Atmos Environ 1978;12:1371-7.

15. Whorton MD, Larson SR, Gordon NJ, Morgan RW. Investigation and work-up of tight building syndrome. J Occup Med 1987;29:142-7.

16. Morris L, Hawkins L. The role of stress in the sick building syndrome. In: Seifert B, Esdorn H, Fisher M, Rüden H, Wegner J, ed. Indoor air '87; vol 2 (Environmental tobacco smoke, multicomponent studies, sick buildings, odours and irritants, hyperreactivities and allergies). Berlin: Institute for Water, Soil and Air Hygiene, 1987: $566-71$.

17. Holberg CJ, O'Rourke MK, Lebowitz MD. Multivariate analysis of ambient factors and respiratory effects. Int J Epidemiol 1987; 16:399-410.

18. Pöllman L, Pöllman B. Observations on the "sick building syndrome"' in a newly built large hospital. In: Seifert $B$, Esdorn $H$, Fisher $M$, Rüden $H$, Wegner J, ed. Indoor air '87; vol 2 (Environmental tobacco smoke, mul- ticomponent studies, sick buildings, odours and irritants, hyperreactivities and allergies). Berlin: Institute for Water, Soil and Air Hygiene, 1987:577-81.

19. Jaakola J, Heinonen P, Seppänen O. Mechanical ventilation in an office building and sick building syndrome - a short term trial. In: Seifert B, Esdorn H, Fisher M, Rüden H, Wegner J, ed. Indoor air '87; vol 2 (Environmental tobacco smoke, multicomponent studies, sick buildings, odours and irritants, hyperreactivities and allergies). Berlin: Institute for Water, Soil and Air Hygiene, 1987:454-8.

20. Valbjørn O, Skov P. Influence of indoor climate on the sick building syndrome prevalence. In: Seifert B, Esdorn H, Fisher M, Rüden H, Wegner J, ed. Indoor air '87; vol 2 (Environmental tobacco smoke, multicomponent studies, sick buildings, odours and irritants, hyperreactivities and allergies). Berlin: Institute for Water, Soil and Air Hygiene, 1987:593-7.

21. Main DM, Hogan TJ, Health effects of low-level exposure to formaldehyde. J Occup Med 1983;25:896900.

22. Olsen $\mathrm{JH}$, Dössing $\mathrm{M}$. Formaldehyde induced symptoms in day care centers. Am Ind Hyg Assoc J 1982;43: $366-70$.

23. Widström $\mathbf{J}$, Norbäck D. En inventering av sjuka hus bland företagshälsovårdsanslutna arbetsplatser i Gävleborgs, Kopparbergs.samt Uppsala län [An inventory of sick buildings among workplaces connected to occupational health centers in the counties of Gävleborg, Kopparberg and Uppsala]. In: Arbetsmiljöinstitutet. Proceedings of 37 Nordic Meeting of Work Environment, Aug 29-31, 1988. Göteborg: Arbetsmiljöinstitutet, 1988:292-3.

24. Bond $\mathrm{A}, \mathrm{Lader} \mathrm{M}$. The use of analogue rating scales in rating subjective feelings. Br J Med Psychol 1974;47: $211-8$.

25. Andersson K, Hallgren C, Levin J-O, Nilsson C-A. Chemosorption sampling and analysis of formaldehyde in air: influence of recovery during the simultaneous sampling of formaldehyde, phenol, furfural and furfuryl alcohol. Scand J Work Environ Health 1981;7:282-9.

26. Owen DB. Handbook of statistical tables. London: Pergamon Press, 1962.

27. Saltzman BE. Lognormal model for health risk assessment of fluctuating concentrations. Am Ind Hyg Assoc J 1987; 48:140-9.

28. Greenland S. Modeling and variable selection in epidemiologic analysis. Am J Public Health 1989;79:340-9

29. Empey DW, Laitinen LA, Jacobs L, Gold WM, Nadel JA. Mechanisms of bronchial hyperreactivity in normal subjects after upper respiratory tract infection. Am Rev Respir Dis 1976;113:131-9.

30. Michel I, Norbäck D, Edling C. An epidemiologic study of the relation between symptoms of fatigue, dental amalgam and other factors. Swed Dent J 1989;13:33-8.

31. Göthe C-J, Ancker K, Bjurström R, Holm S, Langworth $\mathrm{S}$. Electric potential differences against the surroundings and discomforts in indoor environments. Ann Occup Hyg 1989;33: 263-7.

32. Berglund $B$, Lindvall $T$. Sensory reactions to "sick buildings." Environ Int 1986;12:147-59.

33. Mølhave L, Bach B, Pedersen OF. Human reactions to low concentrations of volatile organic compounds. Environ Int 1986;12:167-75.

34. Fanger PO. A solution to the sick building mystery. In: Seifert B, Esdorn $H$, Fisher M, Rüden $H$, Wegner J, ed. Indoor air '87; vol 4 (Plenary lectures, index). Berlin: Institute for Water, Soil and Air Hygiene, 1987: $49-55$. 


\section{Appendix}

\section{Measurement items}

I. Symptom items

The responses to the following questions were scored $0=$ no, $1=$ yes:

Have you during the last six months:

Had rashes en the hands or forearms?

Had rashes on the face or throat?

Had eczema?

Had itching hands or forearms?

Had itching face or throat?

Had eye irritation (redness of the eyes)?

Had swollen eyelids?

Often had headache?

Often felt nausea?

Often had nasal catarrh?

Often had a stopped-up nose?

Often felt dryness in the throat?
Often felt as if you would get a cold?

Often had sore throat?

Often had irritative cough?

Often felt tired and out of sorts?

II. Psychosocial rating scales (0 to $100 \%$ )

The subject was asked to mark his or her rating on the presented scales:

How satisfied are you with your work conditions? Totally dissatisfied ......... Perfectly satisfied

How stressful is your work?

No stress $\ldots \ldots \ldots \ldots$ Extremely stressful

How is the climate of cooperation at your workplace?

Very poor $\ldots \ldots \ldots \ldots \ldots \ldots \ldots$. Very good

Received for publication: 9 February 1989 